\title{
Truthmaking and the Mysteries of Emergence
}

Kevin Morris

Penultimate draft; forthcoming in E. Vintiadis and C. Mekios (eds.), Brute Facts (Oxford)

\section{Introduction}

The concept of truthmaking, the idea that when a statement or proposition is true, there is typically something about the world in virtue of which it is true, has garnered much interest in recent metaphysics. Often, the motivation has been the thought that truthmaking can provide a new perspective on an important issue. Thus it has been claimed that truthmaking can be used to advance debates over realism, ontological commitment, fundamentality, physicalism, and levels of reality; to catch "ontological cheaters"; and to distinguish metaphysical issues from linguistic ones. ${ }^{1}$

My focus in what follows will be on the claim that truthmaking can play a substantive role in defining an unproblematic notion of emergence. While "emergence" and related locutions have been used to express a variety of nonequivalent ideas, ${ }^{2}$ in perhaps the most philosophically interesting sense, to say that some property $\mathrm{M}$ is emergent is to say that while instances of $\mathrm{M}$ synchronically depend on instances of other properties, instances of $\mathrm{M}$ are truly novel additions to the world; and instances of $\mathrm{M}$ are genuine additions to the world, at least in part, in virtue of making a unique and distinctive causal contribution. It has often been claimed, moreover, that there is no explanation, in principle, for why such properties emerge or arise in the way that they do: this is a brute, inexplicable

\footnotetext{
${ }^{1}$ See Armstrong 1989 and 2004, Barnes 2012, Cameron and Barnes 2007, Cameron 2008 and 2010, Heil 2003 and 2012 , and Sharpe (unpublished ms); for critical discussion, see Merricks 2007, Schaffer 2008, and Schulte 2014. For accounts of truthmaking, see Armstrong 2004, Mulligan et. al. 1984, and the papers in Beebee and Dodd 2005 and Lowe and Rami 2009.

2 For example, in addition to the notion here of interest, "emergent" has been used in a weak metaphysical sense to denote any property of a whole that is not easily attributed to its constituents. In this sense, perhaps liquidity is emergent, since the characteristics associated with being liquid are not easily attributed to the basic constituents of liquids. Likewise, in an epistemic sense, "emergent" has been used to denote properties that cannot, due to epistemic and conceptual limitations of human thinkers, be predicted from more basic constituents of the world. While these notions of emergence raise a number of issues, they seem to be free of the mysteries often thought to beset the more robust sort of emergence here of interest.
} 
kind of determination that must be accepted with "natural piety". Experiential or phenomenal properties are perhaps the best candidate for being emergent in this sense. ${ }^{3}$ Yet despite playing an important role in philosophical discourse over the past 100 years, it has often been thought that there is something mysterious about this notion of emergence: some have challenged the putative "ontological weight" of emergent properties, and whether the dependence of emergent properties is consistent with these properties being genuinely novel, over-and-above other properties; others have likewise questioned the proposed causal efficacy of emergent properties, and whether the dependence of emergent properties is consistent with attributing to them distinctive, nonredundant causal powers; others have questioned the intelligibility of properties arising from or being determined by other properties as matter of brute, inexplicable fact. ${ }^{4}$ It has recently been argued, however, that these and related worries - essentially, worries about the very coherence and intelligibility of emergence — arise from couching emergence in a "levels-based ontology" in which emergent properties are "higherlevel". Further, it has been claimed that once emergent properties are instead characterized as those that, while "ontologically dependent" are yet needed as truthmakers (and in this sense fundamental), emergence and emergent properties prove to be unproblematic. Call this notion "emergence $\mathrm{T}$ ". As Elizabeth Barnes (2012: 874) puts it, the idea is that once emergence is articulated as emergence ${ }_{\mathrm{T}}$, "many of the standard puzzles and problems for emergence-and in particular, the worry that emergence is 'mysterious' - can be resolved'.

While I am cautiously optimistic about the philosophical usefulness of truthmaking, I will argue that there is reason to doubt that truthmaking can play an important role in formulating an unproblematic yet recognizable notion of emergence. On the one hand, I believe that the truthmaking-based concept of emergence that Barnes develops in "Emergence and Fundamentality",

\footnotetext{
${ }^{3}$ Alexander 1920, Broad 1925, Chalmers 1996, and Vision 2011 argue that there are emergent features in roughly this sense. The coherence of a notion of emergence along these lines is defended in McLaughlin 1992, O'Connor 1994, Stephan 1997, and Wilson 2005. Horgan 1993 and Melnyk 2003 appeal to the coherence of emergence in the context of arguing that physicalism cannot be defined in terms of supervenience: emergent properties, they contend, are taken to supervene on physical properties, yet have no place in a genuinely physicalist outlook.

${ }^{4}$ See, for example, Howell 2009, Kim 1999, 2010, and 2011, Nagel 1979, Pepper 1926, and Strawson 2006.
} 
as well as in coauthored work with Ross Cameron, succeeds in avoiding the "mysteries of emergence", including worries about the alleged brute determination of emergent properties by more basic features of the world. On the other hand, however, I believe that this result is secured largely if not entirely by the notion of ontological dependence that emergence ${ }_{\mathrm{T}}$ employs, and that the appeal to truthmaking, in contrast, is superfluous. Moreover, while the truthmaking-based concept of emergence as such may not be mysterious, it appears that standard concerns about emergence and emergent properties can be straightforwardly restated for a subset of those properties taken to be emergent $\mathrm{T}$. I will argue for these claims in Section 3. In Section 4 I will argue that it is consistent with truthmaking being unable to play a substantive role in emergentism that truthmaking can play a more significant role in characterizing an attractive middle ground between reductive and nonreductive conceptions of physicalism.

I will begin by sketching the two central notions of the truthmaking-based precisification of emergence: the notion of being needed as a truthmaker and the notion of ontological dependence.

\section{Truthmaking and Ontological Dependence in Emergence}

While there is an extensive literature on truthmaking, ${ }^{5}$ the basic idea is that when some statement, representation, or proposition (a truthbearer) is true, there is something about the world in virtue of which it is true. Regarding the notion of being needed as a truthmaker, Cameron and Barnes (2007: 28) write that to be needed as a truthmaker is to be amongst "all and only those things which God needs to create in order to make the world how it is... the minimal contents of God's 'ontological shopping basket'". In contrast, items not needed as truthmakers need not be included in God's "ontological shopping basket", as they "come for free" once God has created those items that are needed as truthmakers. For example, tablehood is not needed as a truthmaker, since the basic physical constituents of reality, suitably arranged, suffice to make true ascriptions of the predicate "is a table". Likewise, liquidity is not needed as a truthmaker, given that the basic physical constituents

\footnotetext{
${ }^{5}$ See fn. 1.
} 
of reality, and how they are propertied and related, suffice to make true ascriptions of "is a liquid". That emergent features are needed as truthmakers appears to be intended as an account of "emergent novelty" - as a way of expressing the idea that emergent properties are genuine additions to the world, over-and-above those properties upon which they depend. ${ }^{6}$

While Barnes (2012: 885) glosses the ontological dependence of emergent properties as the idea that they are "caused and sustained" by other properties, in the context of emergence ontological dependence is officially understood as amounting to the impossibility of independent existence: to be ontologically dependent is to be incapable of "lonely existence". A table, for example, is ontologically dependent: one cannot just create a table, for in order to create a table, one must also create the entities that compose the table. Importantly, for a property to be ontologically dependent- "dependento"- does not require that the distribution of that property is fixed or determined by other properties. For example (Barnes 2012: 890):

Mass tropes are arguably dependent-certain other tropes (shape and size tropes, perhaps) must exist, and relate to each other in specific ways, in order for a mass trope to exist.

However,

Mass is something quite distinct from shape and size, and ostensibly cannot be fixed just by shape and size. It is just that it cannot exist independently of them.

That emergence $\mathrm{T}_{\mathrm{T}}$ does not require that emergent properties are fixed or determined by other properties might seem unwelcome. For example, it would seem to follow from this that a property

\footnotetext{
${ }^{6}$ Several points are worth noting. First, while Cameron and Barnes do not develop emergence $\mathrm{T}$ specifically as a thesis about properties, my focus on properties is consistent with much of the literature on emergence. Second, while Cameron and Barnes 2007 focuses on the idea that emergent properties are needed as truthmakers and in this sense fundamental, Barnes 2012 takes fundamentality to be primitive. However, Barnes 2012 nonetheless suggests that whether something is needed as a truthmaker is a guide to whether it is fundamental. Moreover, the gloss on truthmaking offered in Cameron and Barnes 2007-that to be needed as a truthmaker is to be "among the minimal contents of God's 'ontological shopping basket" — corresponds to the gloss on fundamentality - "the fundamental entities are all and only those entities which God needs to create in order to make the world how it is"- given in Barnes 2012. Finally, it should be conceded that the notion of being needed as a truthmaker is not entirely perspicuous. However, while I will have something to say about this (see Section 3), this is not a concern that I will pursue in detail.
} 
may count as emergent $\mathrm{T}_{\mathrm{T}}$ without emerging or arising from anything. It would also seem to follow that no particular thesis of supervenience is entailed by the claim that a property $\mathrm{M}$ is emergent $_{\mathrm{T}}{ }^{7}$ Likewise, it appears that nontraditional candidates for being emergent, such as mass, are candidates for being emergent $\mathrm{T}_{\mathrm{T}}$. Yet while I will have more to say about the role of dependence $\mathrm{O}$ in the truthmaking-based concept of emergence, I do not think that emergence ${ }_{\mathrm{T}}$ should be dismissed simply because it has these results. For one thing, while to say that a property $\mathrm{M}$ is emergent $\mathrm{T}_{\mathrm{T}}$ does not entail that instances of $\mathrm{M}$ are fixed or determined by other properties, this is prima facie consistent with

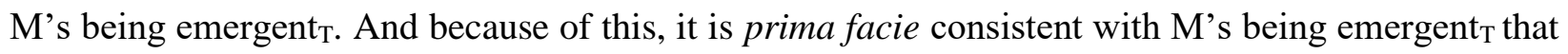
instances of $\mathrm{M}$ emerge from other properties, even if this is not entailed by M's being emergent ${ }_{\mathrm{T}}$. Likewise, while perhaps nontraditional candidates for being emergent are candidates for being emergent $_{\mathrm{T}}$, emergence $\mathrm{T}_{\mathrm{T}}$ does not appear to exclude any traditional candidates, precisely because it adopts a more permissive conception of "emergent dependence". In particular, emergence Tefines $^{-}$ emergent dependence in terms of dependence, , which is weaker than traditional notions of emergent dependence to the extent that it does not involve a fixing or determination requirement. Related remarks apply to the observation that nothing in emergence ${ }_{\mathrm{T}}$ requires that emergent properties arise from or indeed emerge from other properties, as the example of mass also makes clear. ${ }^{8}$

\section{Truthmaking, Dependence, and the Mysteries of Emergence}

Cameron and Barnes are aware that emergence has often been viewed with suspicion, and they appear to hold that the central advantage of emergence ${ }_{\mathrm{T}}$ is that it clearly and unambiguously avoids the alleged mysteries of emergence. I will now consider these mysteries in more detail and how the

\footnotetext{
${ }^{7}$ Cameron and Barnes (2007: 28) appear to regard this as a benefit: emergence ${ }_{\mathrm{T}}$, they write, permits one to remain "blissfully neutral" on whether emergent properties supervene on other properties. In contrast, Howell 2009, Kim 1999 and 2011 , McLaughlin 1992, and van Cleve 1990 take supervenience to be a constitutive aspect of emergence, and seem to suppose that this is how emergence was understood in the classic discussions in Alexander 1920, Broad 1925, and elsewhere. See Section 3 for related discussion.

${ }^{8}$ Pearson forthcoming, in contrast, rejects emergence $\mathrm{T}_{\mathrm{T}}$ as an account of emergence, in part, on the grounds that it countenancing nonstandard cases and fails to capture the idea of emergent properties arising or emerging from more basic constituents (and in this sense fails to capture the idea of emergence as an asymmetric relation of dependence). While I am uncertain about some of the details of Pearson's arguments, his critique of emergence ${ }_{\mathrm{T}}$ is consonant with the issues that I raise below.
} 
truthmaking-based concept addresses them. My claim will be that in each case, truthmaking plays a negligible role and that there is an important sense in which the appeal to emergence $\mathrm{T}_{\mathrm{T}}$ masks, rather than answers, the standard concerns about emergence and emergent properties.

\section{1 "Ontological Weight" and Brute Determination}

Barnes (2012: 896) characterizes the problem of "ontological weight" as the problem

... of saying why, exactly, we need to treat emergent entities with ontological seriousness. Emergent entities, on the levels picture, are not absolutely fundamental — they are not the basic, indivisible building blocks of matter —or at least they are very different from the other sorts of things that are absolutely fundamental. But they are not just another variety of complex entity...

The idea seems to be something like this. Suppose that emergent properties are taken to be "higher-level", and not among the "basic, indivisible building blocks of matter". In this case, the challenge is to say why emergent properties should be treated with "ontological seriousness" and regarded as genuinely novel additions to the world in a way that liquidity, for example, is not. While Cameron and Barnes say little about the details involved here, it is worth noting that there are several facets to the challenge. For one thing, one may wonder just how emergent novelty should be understood. While this has often been cashed out in terms of causal distinctiveness - an idea I will address separately in Section 3.2 - the proposals sometimes offered here are hardly paradigms of clarity and rigor. For example, one may worry that claiming that emergent properties are novel in virtue of being "simple" or "nonstructural" or "nonfunctional" or "qualitative" or "nonnatural" is either obscure, or else fails to specify why such properties ought to be regarded as truly novel additions to the world. ${ }^{9}$ Second, and perhaps more significantly, one might question whether the idea

\footnotetext{
${ }^{9}$ It would take me too far afield to go into detail about all of these proposals. The "nonnatural" character of emergent properties is associated with G.E. Moore's remarks on goodness. However, it is not clear what Moore meant in calling goodness "nonnatural", or why, given what he meant, a commitment to "nonnatural properties" should be thought to have significant metaphysical consequences (Dreier 2006; see also Polger 2013). O'Connor 1994 takes emergent properties to be "nonstructural". In pursuing a kind of dualism about experience, Chalmers 1996 emphasizes that phenomenal properties seem to be neither
} 
that emergent properties are over-and-above other properties in a way that liquidity is not can really be coherently combined with the idea that emergent properties somehow depend on more basic aspects of the world. Robert Howell (2009), for example, forcefully argues that given plausible theses about property individuation, it cannot be maintained that emergent properties are both genuinely novel, over-and-above the physical properties that are instantiated, and that they depend on and are strictly determined by the distribution of physical properties. In this way, he claims that genuine emergent novelty is inconsistent with the metaphysical supervenience of emergent properties on physical properties. ${ }^{10}$

It is plausible, as Barnes claims (2012: 897), that concerns along these lines cannot be straightforwardly pressed against emergence deep question of why emergent ${ }_{\mathrm{T}}$ properties should be granted "ontological weight". After all, they are needed as truthmakers and in this sense fundamental. Likewise, while Cameron and Barnes do not focus on concerns about alternative conceptions of emergent novelty, it should be granted that the notion of being needed as a truthmaker provides a reasonably clear articulation of emergent novelty. ${ }^{11}$ Finally, and perhaps most importantly, it should be granted that there is no incompatibility between being needed as a truthmaker and being dependento. For given that dependento properties need not be fixed or determined by other properties, it is hard to see why being dependento should preclude being needed as a truthmaker, and thus why being dependento should be inconsistent with emergent novelty so understood. Consider the example of mass. To say that mass is dependento is to

"functional" nor "structural"; for critical discussion, see Stoljar 2006. The idea that emergent properties are "qualitative" is not helpful if one thinks that all properties are in a way qualities (Heil 2003) or that while not all properties are qualities, qualities are part of the basic building blocks of reality (Unger 1998).

${ }^{10}$ On this basis, Howell (2009) claims that non-physicalist emergentisms cannot be offered as a counterexample to definitions of physicalism in terms of metaphysical supervenience (see fn. 3). For discussion of Howell's defense of supervenience-based definitions of physicalism, see Morris 2014b.

11 One might, however, question the depth of characterizing emergent novelty in terms of the notion of being needed as a truthmaker. Given that some property $\mathrm{M}$ is both needed as a truthmaker and dependento, it is natural to wonder why $\mathrm{M}$ is needed as a truthmaker. It is also natural to think that this question should have a nontrivial answer. Yet the most straightforward answers would seem to either appeal to the alternative conceptions of emergent novelty mentioned in the text, or to the dependence of

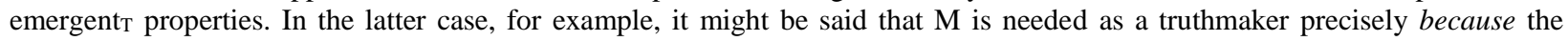
distribution of $\mathrm{M}$ is not determined by other properties; likewise, it might be said that while the distribution of $\mathrm{M}$ is in some manner determined by other properties, this holds in a weak enough way that $M$ is nonetheless needed as a truthmaker for ascriptions of M. While there is certainly more that could be said here, I will not pursue concerns along these lines in detail. 
say, at least, that mass cannot be instantiated apart from all other properties. But it does not follow from this that the distribution of mass is fixed or determined by other properties. And if the distribution of mass is not so fixed, it is difficult to see why mass should not be needed to make true attributions of mass, and thus be needed as a truthmaker despite being dependent ${ }_{O}$.

On the other hand, I believe that it would be a mistake to think that the idea that emergent properties are needed as truthmakers is doing the work here. First, insofar as the proposals for understanding emergent novelty mentioned above-that emergent properties are "simple" or "nonstructural" or "nonfunctional" or "qualitative" or "nonnatural"-have clear content, it would seem that emergent novelty in these senses is likewise consistent with dependence ${ }_{o}$. For example, it appears that one can consistently maintain that a property is both "nonnatural" or "simple" or "nonfunctional", and yet cannot be instantiated apart from all other properties, and is thus dependento. Second, while being needed as a truthmaker is consistent with being dependento, being needed as a truthmaker fits uneasily with a stronger notion of dependence that involves a fixing or determination component. Such a notion may be understood, at least roughly, in terms of supervenience, and may be referred to as "dependences". ${ }^{12}$ It is difficult to see, for example, why a property should be needed as a truthmaker if its instances follow as a matter of strict necessity from more basic constituents of the world-essentially, if that property metaphysically supervenes on other properties. ${ }^{13}$ If the experiential states of organisms, for example, follow as a matter of strict necessity from physical states of the world, it would seem that physical states of the world will suffice to make true attributions of experiential properties. ${ }^{14}$ Of course, if some weaker, perhaps

\footnotetext{
12 Supervenience, and the idea that supervenient properties are determined by other properties, expresses a notion of "levels" (Kim 2002; see also Heil 2003). However, this is not the same notion of levels that Cameron and Barnes explicitly critique, which is a broadly mereological conception. These notions of levels are distinct because levels ordered in terms of supervenience or determination relations may not be ordered mereologically.

${ }^{13}$ It has sometimes been held that emergent properties nomologically supervene on other properties and that the nomological, rather than metaphysical, supervenience of emergent properties distinguishes emergentism from more physicalistic views (Chalmers 1996, McLaughlin 1992, van Cleve 1990). However, the metaphysical supervenience of emergent properties has been taken seriously by a number of writers (Horgan 1993, Melnyk 2003, Wilson 2005; see Howell 2009 for discussion).

${ }^{14}$ It might be claimed that a property can both be needed as a truthmaker and yet metaphysically supervene on other properties. While perhaps there are accounts of truthmaking that have this result, the gloss on being needed as a truthmaker that Cameron
} 
merely nomological, notion of determination is employed, perhaps a property so determined may yet be needed as a truthmaker. But the same could be said of the notions of emergent novelty mentioned above. For example, one may respond to concerns about the coherence of maintaining that a property is both "nonnatural" and yet strictly determined by physical or natural properties by weakening the sense of determination at issue, retreating, perhaps, to a thesis of nomological rather than strict or metaphysical determination. ${ }^{15}$

While I will return to some of these issues below, the present discussion can be summarized as follows. Emergence $\mathrm{T}_{\mathrm{T}}$ has two components, an account of emergent novelty (being needed as a truthmaker) and an account of emergent dependence (being dependento). These components appear to be consistent, and emergence ${ }_{\mathrm{T}}$ seems to avoid mysteries surrounding the "ontological weight" of emergent properties. However, the idea that emergent $\mathrm{T}_{\mathrm{T}}$ properties are needed as truthmakers appears to be superfluous. First, all standard accounts of emergent novelty are consistent with the ontological dependence of emergent properties. Second, the truthmaking-based conception of emergent novelty fits at least as uneasily as alternative conceptions of emergent novelty with conceptions of emergent dependence that do have a determination or fixing component.

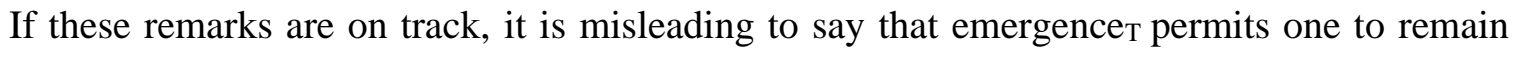
"blissfully neutral" on whether emergent properties supervene on other properties (Cameron and Barnes 2007, 28). ${ }^{16}$ It is true that a thesis of emergence $\mathrm{T}_{\mathrm{T}}$ does not entail any particular thesis of supervenience: emergence ${ }_{T}$ is defined in terms of dependence $O$, and a property can be dependento without its instances being determined by other properties. But if emergent novelty is understood as

\footnotetext{
and Barnes 2007 provide - that to be needed as a truthmaker is to be amongst "all and only those things which God needs to create in order to make the world how it is... the minimal contents of God's 'ontological shopping basket" —provides no reason for thinking that this is the case, since properties that metaphysically supervene on other properties will not, it would seem, be among the "minimal contents of God's 'ontological shopping basket". Further, I am inclined to think that the kind of strategies for combining being needed as a truthmaker with metaphysical supervenience-for example, strategies that emphasize the putative explanatory character of truthmaking and the putative non-explanatory character of supervenience-will be available on alternative ways of understanding emergent novelty as well.

${ }^{15}$ See fn. 13.

${ }^{16}$ See fn. 7.
} 
being needed as a truthmaker, one should probably deny that emergent properties metaphysically supervene on other properties. This, again, is a familiar situation for the emergentist: given tension between emergent novelty and the idea that emergent properties are determined by other properties, the emergentist may aim to weaken the way in which emergent properties are taken to be determined by other properties. Similarly, the emergentist may claim that emergent properties have "ontological weight" unlike liquidity on the grounds that emergent properties are determined by other properties in a weaker sense than liquidity. In this way, when emergent properties are understood in truthmaking-theoretic terms, the options concerning supervenience are much like those traditionally thought available to the emergentist.

If the present diagnosis is accepted, it would also seem that there is an important sense in which emergence $\mathrm{T}_{\mathrm{T}}$ masks, rather than answers, concerns about why emergent properties should be treated with "ontological seriousness" and whether such a treatment is consistent with emergent

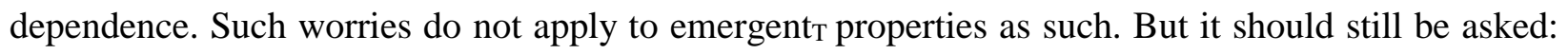
what about the emergent $\mathrm{T}_{\mathrm{T}}$ properties that are not merely dependento, but moreover dependents? Is the dependences of these features consistent with the claim that they carry "ontological weight"? These questions are not answered, or even addressed, by the appeal to emergence ${ }_{\mathrm{T}}$. Importantly, it ought to be conceded that these are legitimate questions. While I claimed in Section 2 that emergence Thould $_{\mathrm{T}}$ not be rejected on the grounds that it does not require that emergent properties are determined by

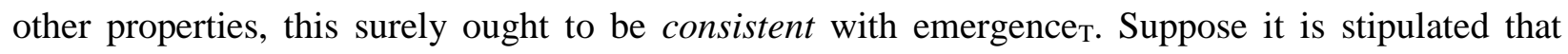
emergence $_{\mathrm{T}}$ excludes properties that are not merely dependento, but moreover dependents. In this case, it would be implausible to maintain that emergence ${ }_{\mathrm{T}}$ is a precisification of emergence in the sense of interest. After all, many traditional candidates for emergence, including experiential properties, have been taken to be determined by other properties. Further, independently of emergentism, such properties do not seem to depend on other properties merely in the way in which mass, perhaps, depends for its instantiation on shape and size. In general, it would be a poor defense 
of emergence to simply restrict emergence to properties that are dependent merely in the way that mass, perhaps, is dependent with respect to shape and size.

Consider, likewise, the important issue of brute determination. This, again, is the idea that there is no explanation, in principle, for why emergent features arise from, or are determined by, certain properties and conditions. Some philosophers have found this to be a kind of magic that ought to be avoided if at all possible; Galen Strawson, for example, appears to regard such brute determination as strictly incoherent, and uses this observation to move from the denial reductionism about experience to a kind of panpsychism. ${ }^{17}$ It is true, of course, that in saying that some property $\mathrm{M}$ is emergent $\mathrm{T}_{\mathrm{T}}$, one cannot be faulted for thereby supposing that instances of $\mathrm{M}$ arise as a matter of inexplicable fact from other properties, and so for endorsing an obscure bruteness in the very structure of reality. That one cannot be so faulted, however, is not because emergent $\mathrm{T}_{\mathrm{T}}$ features are taken to bear an intelligible relationship to the properties from which they arise. Rather, it is because emergence $_{\mathrm{T}}$ is defined using dependence $\mathrm{o}$ and dependento properties need not arise from or be determined by other properties. That emergent $\mathrm{T}_{\mathrm{T}}$ properties are needed as truthmakers is beside the point, and if the notion of emergence ${ }_{\mathrm{T}}$ cannot be faulted for entailing a mysterious kind of brute determination, this is simply in virtue of not entailing any substantive determination thesis.

As with concerns about the "ontological weight" of emergent properties, while concerns about brute determination do not apply to emergent $\mathrm{T}_{\mathrm{T}}$ properties as such, they can be straightforwardly developed for a subset of properties taken to be emergent $\mathrm{T}_{\mathrm{T}}$, those that are dependents and not merely dependento. Now, on the one hand, one may simply concede that there is no explanation, in principle, for why these properties are determined in the way that they are and that truthmaking offers no distinctive options when it comes to saying why such brute determination is or is not objectionable. On the other hand, however, if one aims to deny that emergent $\mathrm{T}_{\mathrm{T}}$ properties that are

\footnotetext{
17 Strawson 2006; see also Nagel 1979. Horgan 1993 and Melnyk 2003 claim that brute determination or supervenience is coherent, yet is incompatible with physicalism; but see Howell 2009 and Polger 2013 for discussion.
} 
dependents are determined by other properties as a matter of brute and inexplicable fact, the appeal to truthmaking may prove to only make this task more daunting. In particular, the determination of emergent properties will have to be made intelligible in a way that is consistent with emergent properties being needed as truthmakers. While perhaps there is a way to do this, there is prima facie reason for doubt. Standard strategies for making intelligible why a property is determined by other properties appear to have the consequence that the property so determined is plainly not needed as a truthmaker. Consider, for example, causal-functionalist views of physical realization, according to which physical realization is taken to involve a physical property playing the causal-functional role individuative of the realized property. It is plausible that properties that are physically realized in this sense thereby bear an intelligible relationship to physical reality and that a thesis of physical realization can explain why certain properties are determined by other properties. ${ }^{18}$ But it is implausible to hold that properties that are physically realized in this sense are needed as truthmakers. While physical realization so understood may preclude emergent novelty in all of the senses mentioned above, the issue is especially poignant on the truthmaking-based approach, since it is especially doubtful that properties that are physically realized are needed as truthmakers.

First, then, the appeal to emergence $\mathrm{T}_{\mathrm{T}}$ masks, rather than answers, concerns about brute determination: it defines emergence in terms of dependence o, which does not have a determination component; at the same time, however, the extension of emergence $\mathrm{T}_{\mathrm{T}}$ ought to include properties that are determined by other properties. Second, emergence ${ }_{T}$ may make concerns about brute determination even more problematic than they would be otherwise. This is because, insofar as one aims to make intelligible why an emergent $\mathrm{T}_{\mathrm{T}}$ property is determined by other properties, that emergent $_{\mathrm{T}}$ properties are needed as truthmakers may prove to limit the strategies available for accomplishing this task.

${ }^{18}$ See, for example, Kim 1998 and Melnyk 2003. For related discussion, see Morris 2010. 
In this section, I considered several related mysteries of emergence. In each case, I argued that the truthmaking-based notion of emergence avoids the mystery by weakening the requisite dependence of emergent properties. Further, I argued that to the extent that emergence $\mathrm{T}_{\mathrm{T}}$ ought to be consistent with more demanding varieties of dependence, there is a good sense in which emergence ignores these mysteries. Finally, in no case did the idea that emergent $\mathrm{T}_{\mathrm{T}}$ properties are needed as truthmakers appear to be doing any substantive work. Because of this, while I couched my discussion in terms of emergence ${ }_{\mathrm{T}}$, my conclusions can be understood as a critique of not so much of emergence $_{\mathrm{T}}$ but rather of truthmaking: if my arguments are successful, they call into question a thesis about the usefulness of truthmaking, namely that truthmaking has a substantive role to play in articulating an unproblematic yet recognizable concept of emergence.

\subsection{Emergence ${ }_{T}$ and Emergent Causation}

Emergentists have wished to claim that emergent properties are causally efficacious and figure as causes. Indeed, they have often claimed that the causal powers of emergent properties are unique and nonredundant - that to give a complete causal account of the occurrence of certain events, one must mention emergent properties. This specifies a further variety of emergent novelty: emergent properties are novel, at least in part, in virtue of making a distinctive and nonredundant causal contribution to the course of events. Yet it has been thought that the proposed causal efficacy of emergent properties is problematic, ${ }^{19}$ and Cameron and Barnes appear to regard this as a core challenge to emergence. ${ }^{20}$ They (2007: 28) present the challenge as concerning how "within a physicalist ontology, a higher-level entity could causally impact the behavior of basic-level entities". Similarly, Barnes (2012: 894-95) writes:

Emergent entities are not, ex hypothesis, part of the very basic building blocks of matter... yet it is often assumed that all causation can be explained solely in terms of

\footnotetext{
${ }^{19}$ See Kim 1999 and 2011.

${ }^{20}$ See Cameron and Barnes 2007: 28 and Barnes 2012: 894-97.
} 
those basic building blocks. So if emergent entities have causal powers... then we have a problem.

The idea here is something like as follows. On a levels-based ontology, all causation is claimed to boil down to the most fundamental entities or features, the "basic building blocks of matter". This is sometimes expressed as a thesis of "causal completeness" or "self-sufficiency", according to which occurrences in the fundamental domain, if they have a sufficient cause at a time, have a sufficient cause from the fundamental domain at that time. A physicalist maintains that the physical domain is complete or self-sufficient in something like this way. Given this, however, it is not easy to make sense of emergent causation. First, if all causation boils down to the "basic building blocks of matter", and emergent properties are not among these building blocks, it makes it difficult to see how emergent properties could have unique or nonredundant causal powers. This will especially be the case with respect to occurrences that involve these basic building blocks, given that any such occurrence will have a sufficient cause from the basic building blocks if it has a sufficient cause at all. The worry here concerns how emergent properties can have distinctive powers, and so play a unique and nonredundant causal role. Second, it can furthermore be argued that attributing "redundant powers" to emergent properties is unpalatable on the grounds that it would entail a bizarre double counting of causes. In particular, it would result in there being occurrences that have sufficient causes from the basic building blocks, yet furthermore have instances of emergent properties as causes. If one regards this as implausible, the conclusion is that emergent properties are at best epiphenomenal: they do not have distinctive and nonredundant powers and they do not have redundant powers either.

Cameron and Barnes (2007: 28) appear to hold that emergence $\mathrm{T}_{\mathrm{T}}$ answers these concerns by denying that what is fundamental corresponds to "the ultimate constituents of matter":

...once levels have been rejected the causal claim we have warrant to appears to be not 'all causation is explainable in terms of basic-level entities', but rather 'all 
causation is explainable in terms of truthmakers'. But...the emergent entities count as truthmakers.

Barnes (2012: 895-96) puts the idea as follows:

Once we have levels in place, the physicalist then claims warrant to explain all causation solely in terms of what is absolutely fundamental (the very basic things), which will never include emergent entities. But the analogous claim for the ontological structure assumed here looks to be this: all causation can be explained solely in terms of what is fundamental. In that case, of course, there is no causation problem for emergence, since emergent entities are fundamental (just not independent).

That is, on emergence ${ }_{\mathrm{T}}$, emergent properties may be included in a presumptively causally self-sufficient domain of fundamental reality, and hence may have unique powers and figure as nonredundant causes. Further, as the example of mass makes clear, there is no presumption that emergent $_{\mathrm{T}}$ features are nonphysical; hence, attributing distinctive causal powers to emergent $\mathrm{T}_{\mathrm{T}}$ properties is consistent with the self-sufficiency of the physical domain.

My response parallels the discussion in Section 3.1. First, it should be conceded that emergent $_{\mathrm{T}}$ features are not automatically excluded from any self-sufficient domain of fundamental reality. As with the concerns about emergence discussed in Section 3.1, this result is secured by denying that emergent $\mathrm{T}_{\mathrm{T}}$ features must be regarded as arising from features in a presumptively selfsufficient domain. But it should still be asked: among putative emergent $\mathrm{T}_{\mathrm{T}}$ properties, what about those that are not merely dependento, but moreover dependents? Can these properties have nonredundant powers, while also arising from other properties? Can those emergent $\mathrm{T}$ properties that are dependents do distinctive causal work? However these questions are answered, it appears irrelevant that emergent $\mathrm{T}_{\mathrm{T}}$ properties are needed as a truthmakers. The issue concerns, rather, whether a feature that arises from or is determined by properties in a self-sufficient domain can itself have 
distinctive and nonredundant powers, especially with respect to occurrences in the domain from which it arises.

Suppose, moreover, that these questions are answered negatively. In other words, suppose that if some domain D is causally self-sufficient and some property $\mathrm{M}$ is not included in D but rather arises from properties in $\mathrm{D}$, any event brought about by an instance of $\mathrm{M}$ will have a sufficient cause from D. Could it nonetheless be maintained that instances of $\mathrm{M}$ are genuine causes, even though the events that they cause also have distinct and sufficient causes from D? This is a controversial issue, and it has often been thought that how it is answered will depend on the strength with which instances of $\mathrm{M}$ are determined by properties from D. For example, it has been claimed that if instances of $\mathrm{M}$ follow as a matter of strict necessity from properties in $\mathrm{D}$, it is unproblematic to hold that events with sufficient causes from $\mathrm{D}$ also have instances of $\mathrm{M}$ as causes, but that if the connection is weaker, the result is a bizarre kind of "overdetermination"- a kind of pervasive, systematic and yet inexplicable correlation of causes. ${ }^{21}$ While there is much that can be said here, the modest point is that the defender of emergence ${ }_{\mathrm{T}}$ appears to face the usual options. For example, it seems that if the problem of emergent causation is understood in the manner that Cameron and Barnes propose, the emergentist will need to specify a suitably intimate kind of determination for

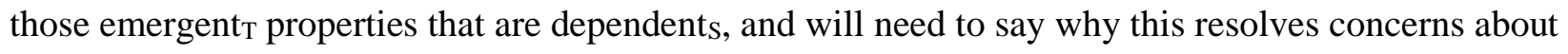
an apparent overabundance of causes. ${ }^{22}$ Further, in addition to the usual issues here, concerns about

\footnotetext{
21 As Eric Funkhouser (2003: 228) puts it, such "overdetermination" would appear to invoke either a sort of "cosmic" coincidence or something like a "divinely arranged prearranged harmony". The distinction between different strengths of determination has figured prominently in responses to Kim's "exclusion problem" for nonreductive physicalism (see Bennett 2003, Marcus 2001, and Yablo 1992; for discussion, see Morris 2015 and Sharpe 2015).

22 The understanding of the problem of emergent causation that Cameron and Barnes appear to endorse takes the self-sufficiency of the physical (or otherwise fundamental) domain as an underived premise. However, Kim $(1999,2011)$ argues that if emergent properties supervene on physical properties, it is difficult to see how an instance of an emergent property could be a distinctive cause of a physical occurrence. The reason, Kim argues, is that whenever an instance of a supervenient property is taken to be a cause of a physical occurrence, its physical base will have at least as much claim to also count as a cause of that occurrence. In effect, Kim claims that the self-sufficiency of the physical is derivable from a thesis of supervenience on the physical. This way of developing the problem of emergent causation is preferable to one that takes the self-sufficiency of the physical as an underived premise, since absent some argument to the contrary the emergentist may simply reject this premise. This, in part, is how the issue of emergent causation differs from the so-called "exclusion problem" that Kim pursues against nonreductive physicalism: the nonreductive physicalist, qua physicalist, cannot reject the self-sufficiency of the physical; in contrast, the
} 
an apparent overabundance of causes will have to be addressed in a way that is consistent with emergent properties being needed as truthmakers. While perhaps there is an account capable of yielding this result, there is some reason for doubt. Again, standard strategies for addressing the present kind of concerns about overdetermination essentially work by "tightening up" the relationship between properties in the presumptively self-sufficient domain and those properties that are determined by properties in that domain. However, at least some of these strategies are prima facie in conflict with the idea that emergent $\mathrm{T}_{\mathrm{T}}$ properties are needed as truthmakers. For example, accounts that appeal to a thesis metaphysical supervenience or strict determination, as well as any account that entails such a thesis, would seem to be unavailable on the truthmaking-based account of emergence. This is because, as I argued in Section 3.1, the claim that a property M metaphysically supervenes on other properties fits uneasily with the claim that $\mathrm{M}$ is needed as truthmaker. As with concerns about brute determination, when it comes to issues about a potential overabundance of causes, truthmaking offers no distinctive options and in fact threatens to make the problem more difficult to address.

\section{Conclusion: Truthmaking and Levels of Reality}

In Section 3, I considered several mysteries of emergence. In each case, while I conceded that emergence $_{\mathrm{T}}$ as such is not mysterious, I argued that the appeal to truthmaking is largely if not entirely superfluous. Moreover, given that dependents properties should be included amongst potentially emergent $_{\mathrm{T}}$ properties, I argued that emergence $\mathrm{T}_{\mathrm{T}}$ essentially glosses over, rather than answers, the worries of those who have been skeptical about the intelligibility of emergence. Aside from these concerns about emergence, my discussions help to bring out why emergence is problematic, if it is. The difficulty is not simply a matter of articulating a decent notion of emergent novelty, but is rather

emergentist, qua emergentist, has no specific commitment the self-sufficiency of the physical. For discussion of Kim's use of this reasoning to defend supervenience-based accounts of physicalism, see Morris 2014a. 
a matter of combining any notion of emergent novelty — including a truthmaking-based notion—with the suggestion that emergent properties arise from and are determined by other properties. ${ }^{23}$

I will conclude by noting that it is consistent with truthmaking being unable to play a substantive role in emergentist metaphysics that it can play a more significant role in characterizing an attractive middle ground between reductive and nonreductive physicalism. In particular, drawing from John Heil and Cameron's work on truthmaking and realism, it might be claimed that truthmaking permits one to accept a purely physical ontology while at the same time accepting what is right about nonreductive physicalism, roughly as follows. ${ }^{24}$ Nonreductive physicalism has often been motivated by the observation that there is no straightforward mapping between the predicates of ordinary discourse and special science on the one hand and the predicates of physics on the other. However, according to a truthmaking-based approach to physicalism, this might be conceded without inferring that there are distinctive higher-level properties. Rather, it might be claimed that the predicates of ordinary discourse and special science apply to things in virtue of how physical entities are propertied and related, and that the claims of ordinary discourse and special science are made true simply by the distribution of physical entities and properties. This idea can be represented as follows: ${ }^{25}$

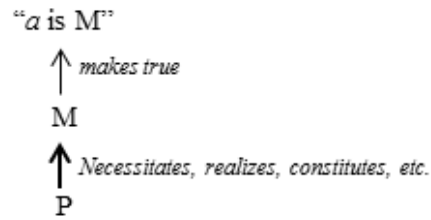

(A)

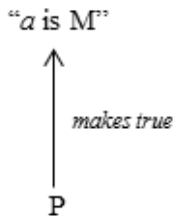

(B)

\footnotetext{
${ }^{23}$ For similar assessments of why emergentism is mysterious, see Howell 2009 and Kim 1999, 2010, and 2011.

${ }^{24}$ See Cameron 2008 and 2010, Heil 2003 and 2012 for ideas along these lines; see also Cameron and Barnes 2007. Neither Heil nor Cameron explicitly develop a truthmaking-based approach to physicalism: Cameron 2008 and 2010 focuses on the issue of material composition while Heil 2003 and 2012 is primarily concerned with whether realism demands that the predicates of a discourse have distinctive properties as semantic values. A truthmaking-based approach to physicalism is suggested in Sharpe (unpublished ms.).

${ }^{25}$ A representation like this was sketched by John Heil at the 2013 NEH Summer Seminar on Metaphysics and Mind.
} 
Figure 1. $P$ is some physical property or state, $M$ is some putative higher-level property or state, and "a is $\mathrm{M}$ " is a statement ascribing a predicate to a thing.

According to the present proposal, truthmaking provides the means to move from (A) to (B) - it provides the conceptual resources to dispense with higher-level properties as intermediaries between higher-level truths and physical reality in favor of a "one level" physical ontology.

What I would like to mark is that this use of truthmaking is quite different from the role in emergentism critiqued in Section 3. Regarding emergence, the crucial truthmaking-based notion is being needed as a truthmaker. But when it comes to properties that are needed as truthmakers, truthmaking does nothing to dispense with levels of reality. Rather, the work is done through weakening the manner in which such properties are said to be dependent: a notion like emergence can dispense with levels of reality, if at all, simply because there are notions of dependence, such as dependence ${ }_{0}$, that do not entail that dependent properties are determined by other properties. In contrast, on a truthmaking-based approach to physicalism, the crucial notion is that of not being needed as a truthmaker. Here, the role of truthmaking consists not in securing the "ontological weight" or novelty of some properties, but rather in specifying a sense in which some properties lack such weight or novelty. That is, the role of truthmaking consists in providing a potential route for dispensing with superfluous properties, rather than in legitimizing properties that are presumed not to be superfluous.

The role that truthmaking might play in dispensing with properties not needed as truthmakers, and so any levels that they occupy, deserves further discussion, and some of the relevant ideas here have been subjected to important criticisms. ${ }^{26}$ For my part, I am not sure that truthmaking can ultimately provide an illuminating approach to physicalist metaphysics, and whether truthmaking is capable of playing the proposed role in physicalism may depend, in part, on how truthmaking is

\footnotetext{
${ }^{26}$ See, for example, Schaffer 2008 and Schulte 2014.
} 
articulated. ${ }^{27}$ My modest point here, however, is that whether or not truthmaking can play a role in this context is quite independent from the minimal role that, I argued, truthmaking can play in emergentist metaphysics. ${ }^{28}$

\section{References}

Alexander, S. 1920. Space, Time and Deity (2 vols). London: Macmillan.

Armstrong, D. 1989. “C.B. Martin, Counterfactuals, Causality, and Conditionals.” In J. Heil (ed), Cause, Mind, and Reality. Dordrecht: Kluwer.

Armstrong, D. 2004. Truth and Truthmakers. Cambridge: Cambridge University Press.

Barnes, E. 2012. “Emergence and Fundamentality.” Mind 121: 873-901.

Beebee, H. and Dodd, J. (eds). 2005. Truth-makers: the Contemporary Debate. Oxford: Oxford University Press.

Bennett, K. 2003. "Why the Exclusion Problem Seems Intractable and How, Just Maybe, to Tract It." Nô̂s 37: 471-97.

Broad, C.D. 1925. The Mind and its Place in Nature. New York: Routledge.

Cameron, R. 2008. “Truthmakers and Ontological Commitment.” Philosophical Studies: 1-18.

Cameron, R. 2010. "How to Have a Radically Minimal Ontology." Philosophical Studies 151: 249-64.

Cameron, R. and Barnes, E. 2007. "A Critical Study of John Heil's From an Ontological Point of View." SWIF Philosophy of Mind Review 6: 22-30.

Chalmers, D. 1996. The Conscious Mind: In Search of a Fundamental Theory. Oxford: Oxford University Press.

Dreier, J. 2006. “Was Moore a Moorean?” In T. Horgan and M. Timmons (eds), Metaethics After Moore. New York: Oxford University Press.

Funkhouser, E. 2002. "Three Varieties of Causal Overdetermination.” Pacific Philosophical Quarterly 83: 335-51.

Heil, J. 2003. From an Ontological Point of View. Oxford: Oxford University Press.

\footnotetext{
${ }^{27}$ See Morris (forthcoming).

${ }^{28}$ A version of this paper was presented at the 2015 Boulder Conference on the History and Philosophy of Science. I would like to thank Nina Emery, Bernard Kobes, Raul Saucedo, and Jessica Wilson, as well as other members of the audience, for helpful comments and questions on that occasion. I would also like to thank Sam Moulton for assistance in preparing the manuscript. Work on this paper was supported, in part, by the National Endowment for the Humanities, although the views expressed here do not necessarily represent those of the Endowment.
} 
Heil, J. 2012. The Universe as We Find It. Oxford: Oxford University Press.

Horgan, T. 1993. "From Supervenience to Superdupervenience: Meeting the Demands of a Material World." Mind 102: 555-86.

Howell, R. 2009. "Emergentism and Supervenience Physicalism.” Australasian Journal of Philosophy 87: 83-98.

Kim, J. 1999. “Making Sense of Emergence.” Philosophical Studies 95: 3-36.

Kim, J. 2002. "The Layered Model: Metaphysical Considerations.” Philosophical Explorations 5: 2-20.

Kim, J. 2005. Physicalism, or Something Near Enough. Princeton: Princeton University Press.

Kim, J. 2010. ““'Supervenient and Yet Not Deducible”: Is There a Coherent Concept of Ontological Emergence?" In Essays in the Metaphysics of Mind. Oxford: Oxford University Press.

Kim, J. 2011. "From Naturalism to Physicalism: Supervenience Redux." Proceedings of the American Philosophical Association 85: 109 -134.

Lowe, E.J. and Rami, A. (eds). 2009. Truth and Truth-making. Stocksfield, UK: Acumen.

Marcus, E. 2001. "Mental Causation: Unnaturalized but not Unnatural.” Philosophy and Phenomenological Research 63: 57-83.

McLaughlin, B. 1992. "The Rise and Fall of British Emergentism.” In A. Beckerman, H. Flohr, \& J. Kim (eds), Emergence or Reduction? Berlin: De Gruyter.

Melnyk, A. 2003. A Physicalist Manifesto. Cambridge: Cambridge University Press.

Merricks, T. 2007. Truth and Ontology. Oxford: Oxford University Press.

Morris, K. 2010. Guidelines for Theorizing About Realization. The Southern Journal of Philosophy 48: 393-416.

Morris, K.2014a. "Causal Closure, Causal Exclusion, and Supervenience Physicalism." Pacific Philosophical Quarterly 95: 72-86.

Morris, K. 2014b. "Supervenience Physicalism, Emergentism, and the Polluted Supervenience Base." Erkenntnis 79: 351-365.

Morris, K. 2015. “Against Disanalogy-Style Responses to the Exclusion Problem.” Philosophia 43: 435-453.

Morris, K. Forthcoming. "Physicalism, Truthmaking, and Levels of Reality: Problems and Prospects." Topoi. 
Mulligan, K., Simons, P., and Smith, B. 1984. "Truth-makers." Philosophy and Phenomenological Research 44: 287-321.

Nagel, T. 1979. "Panpsychism.” In Mortal Questions. Cambridge: Cambridge University Press.

O’Connor, T. 1994. “Emergent Properties.” American Philosophical Quarterly 31: 92-104.

Pearson, O. Forthcoming. Emergence, Dependence, and Fundamentality. Erkenntnis.

Pepper, S. 1926. "Emergence.” The Journal of Philosophy 23: 241-45.

Polger, T. 2013. "Physicalism and Moorean Supervenience." Analytic Philosophy 54: 72-92.

Schaffer, J. 2008. “Truthmaker Commitments.” Philosophical Studies 141: 7-19.

Schulte, P. 2014. “Can Truthmaker Theorists Claim Ontological Free Lunches?” European Journal of Philosophy 22: 249-68.

Sharpe, K. 2015. "Causal Overdetermination and Modal Compatibilism.” Philosophia 43: 1111-31.

Sharpe, K. Unpublished manuscript. "Psychophysical Reduction without Property Identity."

Strawson, G. 2006. "Realistic Monism: Why Physicalism entails Panpsychism." Journal of Consciousness Studies 13: 3-31.

Stephan, A. 1997. “Armchair Arguments Against Emergentism.” Erkenntnis 46: 305-14.

Stoljar, D. 2006. Ignorance and Imagination. Oxford: Oxford University Press.

Unger, P. 1998. "The Mystery of the Physical and the Matter of Qualities: a Paper for Professor Shaffer." Midwest Studies in Philosophy 22: 75-99.

van Cleve, J. 1990. "Mind-Dust or Magic? Panpsychism Versus Emergence.” Philosophical Perspectives 4: 215-26.

Vision, G. 2011. Re-Emergence: Locating Conscious properties in a Material World. Cambridge, MA: The MIT Press.

Wilson, J. 2005. "Supervenience-Based Formulations of Physicalism.” Noûs 39: 426-59.

Yablo, S. 1992. "Mental Causation.” Philosophical Review 101: 245-80. 